\title{
Avaliação do comportamento reológico de suspensões de ossos bovinos calcinados
}

\section{(Evaluation of rheological behavior of suspensions of calcined bovine bones)}

\author{
L. A. Carús, L. Bento, S. R. Bragança \\ Programa de Pós-Graduação em Engenharia de Minas Metalúrgica e de Materiais, \\ Universidade Federal do Rio Grande do Sul, Av. Osvaldo Aranha 99, Porto Alegre, RS, Brasil \\ laucarus@gmail.com
}

\begin{abstract}
Resumo
O uso dos ossos bovinos, subproduto da indústria de gado de corte, na manufatura de produtos cerâmicos pode ser uma alternativa para a valorização desse material no mercado. A produção de um tipo especial de porcelana conhecida como "bone china" emprega cerca de $50 \%$ em peso de ossos calcinados, valorizando a utilização de matéria-prima reciclada na manufatura de louças de qualidade refinada. No caso de porcelanas processadas por colagem de barbotina, o tratamento realizado sobre os ossos, para a remoção da matéria orgânica, afeta diretamente as propriedades reológicas das suspensões contendo esta matéria-prima. O presente estudo avalia a influência das condições de calcinação sobre as características físico-químicas dos ossos para a aplicação em porcelanas processadas por colagem de barbotina. Foram analisadas as propriedades do pó de ossos por meio de espectrocopia por infravermelho, difração de raios X, granulometria a laser, área superficial específica e microscopia eletrônica de varredura. O comportamento reológico dos ossos em suspensão é avaliado em função da concentração de sólidos e do tipo e quantidade de dispersante utilizado em solução. Os resultados obtidos indicam que a temperatura de calcinação afeta as propriedades do pó, alterando sua reologia e a quantidade de dispersante necessária à estabilização das suspensões.
\end{abstract}

Palavras-chave: ossos bovinos, calcinação, reologia, suspensões, hidroxiapatita.

\begin{abstract}
The use of bovine bone, a byproduct of the cow meat industry, in the manufacture of ceramic products can be an alternative for a higher value of such material on the market. The production of a special type of porcelain known as "bone china" employs about $50 \%$ by weight of calcined bones, emphasizing the use of recycled raw material in the manufacture of quality refined porcelain. In the case of porcelain processed by slip casting, the treatment performed on bone, to remove the organic matter directly affects the rheological properties of the slips containing this raw material. The present study evaluates the influence of calcination conditions on the physicochemical characteristics of the bones for use in porcelain processed by slip casting. We analyzed the properties of the bone powder by means of infrared spectroscopy, X-ray diffraction, laser particle size, specific surface area and scanning electron microscopy. The rheological behavior of the bone slip is evaluated as a function of solids concentration and the type and amount of dispersant used in solution. The results indicate that the calcination temperature affects the properties of the powder, changing its rheology and amount of dispersant required for stabilizing suspensions.
\end{abstract}

Keywords: bovine bones, calcination, rheology, slip casting, hydroxyapatite.

\section{INTRODUÇÃO}

O Brasilé o país com maior rebanho comercial do mundo e possui uma ampla oferta de subprodutos da indústria de gado de corte. Entre esses, os ossos bovinos podem apresentar grande interesse à indústria cerâmica brasileira. Após anos sendo empregados em setores de baixa valorização como na produção de ração animal e outros utensílios, o uso de ossos na manufatura de produtos cerâmicos pode ser uma alternativa para valorizar este material no mercado. Assim, os ossos poderiam ser utilizados como matéria-prima na produção de um tipo especial de porcelana conhecida como porcelana de ossos ('bone china'). A formulação da porcelana de ossos provém de uma receita originalmente inglesa na qual se utiliza $50 \%$ em peso de ossos calcinados. Esta formulação foi desenvolvida no século XVIII para que as porcelanas europeias pudessem competir com os produtos chineses [1]. As características estéticas de alvura, brilho e translucidez além da elevada resistência mecânica quando comparada às porcelanas de mesa tradicionais, tornaram a porcelana de ossos um produto atrativo e caro $[2,3]$. Embora muitos países tenham disponibilidade dessa matéria-prima na forma bruta, a manufatura da porcelana de ossos é limitada a poucos países como Grã-Bretanha, Suécia, Japão e Estados Unidos [4]. Este fato pode estar associado ao tratamento prévio dado aos ossos bovinos. Conforme a literatura, os ossos cuja calcinação não for adequadamente efetuada dificultam/impedem o processamento cerâmico, 
principalmente os realizados por via úmida [5]. Para o uso em porcelanas, os ossos passam por um tratamento térmico realizado para remover os constituintes orgânicos que compõem a matriz óssea. Recomenda-se que a temperatura utilizada seja de $1000{ }^{\circ} \mathrm{C}$, garantindo deste modo a total remoção do colágeno, dos proteoglicanos e de outras proteínas que fornecem flexibilidade às unidades ósseas [5]. Outros autores recomendam temperaturas mais baixas, pois além da economia energética, a menor temperatura pode contribuir positivamente para a plasticidade da massa $[4,5]$. Após a calcinação, resta somente a parte inorgânica da matriz óssea, a qual é composta por cálcio $(\mathrm{Ca})$ e fósforo $(\mathrm{P})$ e a relação entre estes componentes $(\mathrm{Ca} / \mathrm{P})$ indica que os cristais são consistuídos de hidroxiapatita $\mathrm{Ca}_{10}\left(\mathrm{PO}_{4}\right)_{6}(\mathrm{OH})$ [6].

No caso de porcelanas fabricadas por colagem de barbotinas (via úmida) o processo exige o controle das propriedades das suspensões: concentração de sólidos, distribuição do tamanho de partículas, morfologia, natureza do líquido de suspensão, temperatura, viscosidade e tixotropia. Também por esse motivo, torna-se necessário garantir que as matérias-primas utilizadas apresentem as características adequadas e uma qualidade constante [7].

O pó de ossos calcinados, quando adicionado à barbotina, dificulta o controle das propriedades reológicas das suspensões. Apesar de aumentar a complexidade do controle de processo, as propriedades obtidas da porcelana de ossos compensam devido ao maior valor agregado dos produtos. Este se deve, principalmente, à maior resistência mecânica $\mathrm{e}$ maior alvura, proporcionada, por meio da formação de fases cristalinas diferenciadas, em relação à porcelana comum. A ausência de contaminantes como óxidos de ferro e titânio também contribuem para este produto ser um dos mais atrativos e caros do mercado $[1,4]$.

O presente trabalho é dirigido ao estudo da influência da temperatura de calcinação sobre as propriedades físicoquímicas dos ossos e sobre o comportamento reológico de uma suspensão contendo esta matéria-prima. A reologia é avaliada em função da viscosidade aparente, da concentração de sólidos e do tipo e quantidade de dispersante utilizado em solução.

\section{MATERIAIS E MÉTODOS}

Os ossos utilizados foram recebidos na forma de pó. Essa matéria-prima é oriunda de uma empresa localizada em S. Leopoldo, RS, e trata-se de um resíduo de corte e usinagem de ossos bovinos, com o propósito de se produzir utensílios decorativos. Portanto, o presente trabalho objetiva também o aproveitamento de um resíduo, sem fins práticos à referida indústria. $\mathrm{O}$ pó de ossos foi calcinado em forno elétrico tipo mufla nas temperaturas de $800^{\circ} \mathrm{C} \mathrm{e} 1000^{\circ} \mathrm{C}$. As temperaturas foram determinadas de acordo com os resultados da análise termogravimétrica (Fig. 1). Em ambos os casos, a taxa de aquecimento do forno, foi de $2,5^{\circ} \mathrm{C} / \mathrm{min}$ com um patamar de $1 \mathrm{~h}$. O material calcinado foi moído em moinho de bolas horizontal por via úmida durante $24 \mathrm{~h}$. A distribuição granulométrica é mostrada na Fig. 1. Posteriormente o
Tabela I - Dispersantes testados utilizados na defloculação das suspensões de pó de ossos calcinados.

[Table I - Dispersants tested in deflocculation of the suspensions of bovine bone calcined.]

\begin{tabular}{lll}
\hline & Dispersantes & Fabricantes \\
\hline A & Solução de silicato $\left(\mathrm{Na}_{2} \mathrm{SiO}_{3}\right)$ & Farma Química S.A \\
B & Solução de poliacrilato de amônia & Sokalan ${ }^{\circledR}$ DCA \\
C & Disperlan L.A/ & Lambra S/A. \\
\hline
\end{tabular}

material moído foi levado a estufa para a secagem durante $24 \mathrm{~h}$.

A caracterização físico-química do pó de ossos foi realizada por meio de análises de espectroscopia de infravermelho por transformada de Fourier - FTIR (Perkin Elmer Spectrum Spotlight 200) na faixa de $4000 \mathrm{~cm}^{-1}$ até $650 \mathrm{~cm}^{-1}$, difração de raios X (Philips X'Pert) com varredura

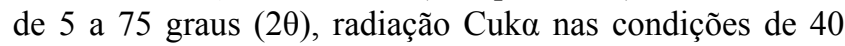
$\mathrm{kV}$ e $40 \mathrm{~mA}$, análise granulométrica (Granulômetro a laser Cilas 1180), área específica, determinada pelo método BET (Quantachrome, Nova 1000), com nitrogênio como gás de adsorção, sendo que as amostras foram pré-tratadas em vácuo por $3 \mathrm{~h}$ a $300^{\circ} \mathrm{C}$. A microestrutura foi analisada em microscopia eletrônica de varredura (Hitachi TM 3000), utilizando-se fita de carbono para deposição do pó.

Após a etapa de caracterização do pó de ossos, as suspensões foram preparadas com água deionizada e diferentes concentrações de sólidos $(55,60,65$ e 70\% em peso), variando-se o tipo e a concentração de dispersante. Os dispersantes avaliados neste trabalho estão mostrados na Tabela I abaixo.

As suspensões tiveram seu comportamento reológico caracterizado em função da taxa de cisalhamento, viscosidade aparente, concentração de sólidos e do percentual de dispersante em solução. Os resultados foram obtidos por viscosímetro Brookfield (LVDV-II com adaptador para pequenos volumes, spindle SC4-18). Antes de dar início ao ensaio, as amostras de suspensões de ossos calcinados foram agitadas durante $1 \mathrm{~min}$ a uma taxa de cisalhamento de 132 $\mathrm{s}^{-1}$, posteriormente as mesmas ficaram em descanso por $30 \mathrm{~s}$.

\section{RESULTADOS E DISCUSSÃO}

Os resultados da análise termogravimétrica (ATG), Fig. 1 , mostram uma acentuada perda de massa até $600^{\circ} \mathrm{C}$, cujos fenômenos envolvidos podem ser associados a perda de água $\left(\sim 100^{\circ} \mathrm{C}\right.$, reação endotérmica) e combustão da matéria orgânica contida nos ossos, com picos de perda de massa e liberação de calor em $300-550^{\circ} \mathrm{C}$. Esta discussão está de acordo com resultados já publicados [6,7].

Não há perda significativa de massa acima de $800{ }^{\circ} \mathrm{C}$, o que indica a remoção completa da matéria orgânica $(\sim 34,8 \%)$. A perda de massa total foi de $35,1 \%$, finalizando em $1000^{\circ} \mathrm{C}$.

Os ossos calcinados nas temperaturas de $800^{\circ} \mathrm{C}$ e $1000^{\circ} \mathrm{C}$ foram avaliados poranálise granulométrica após sua moagem. Os resultados desta análise (Tabela II) mostram que a temperatura de calcinação pouco influenciou na granulometria do pó de 


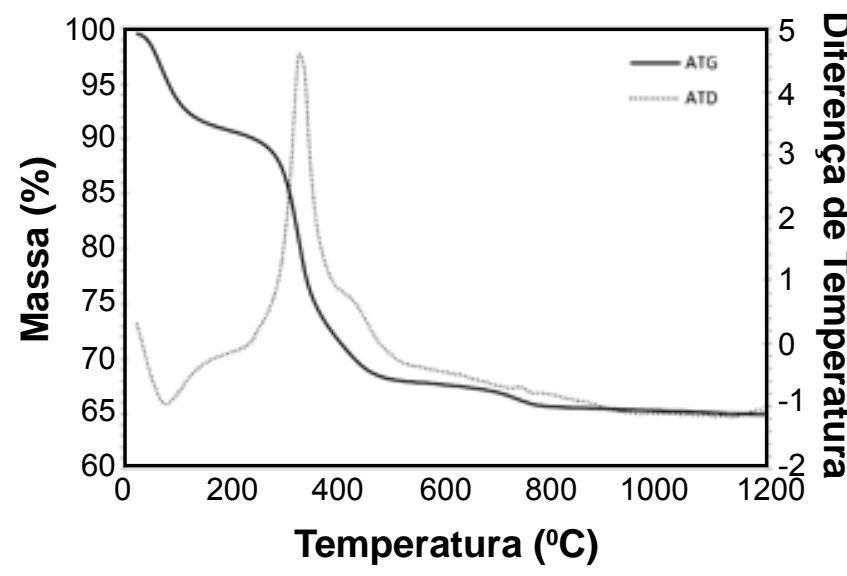

Figura 1: Curvas de análises termogravimétrica (TGA) e termodiferencial (DTA) até $1200^{\circ} \mathrm{C}$ dos ossos bovinos.

[Figure 1: Curves of thermogravimetric analysis (TGA) and thermal differential analysis (DAT) until $1200{ }^{\circ} \mathrm{C}$ of bovine bones.]

Tabela II - Distribuição do tamanho de partículas dos ossos calcinados após $24 \mathrm{~h}$ de moagem.

[Table II - Particle size distribution of bovine bone calcined after 24 h of grinding.]

\begin{tabular}{lll}
\hline Diametro $(\mu \mathrm{m})$ & $800{ }^{\circ} \mathrm{C}$ & $1000{ }^{\circ} \mathrm{C}$ \\
\hline $10 \%<$ & 0,56 & 0,66 \\
$50 \%<$ & 1,80 & 2,21 \\
$90 \%<$ & 11,11 & 9,96 \\
Diamêtro Médio & 3,9 & 3,81 \\
\hline
\end{tabular}

ossos, pois não há diferenças significativas entre o tamanho de partículas dos materiais.

Os resultados de granulometria não mostram diferenças significativas entre os materiais, que pode estar relacionado aos ossos recebidos se encontrarem na forma de pó antes da calcinação. Foi relatado que temperatura mais elevadas propiciam melhor eficiência na moagem de ossos [5]. No entanto, resultados semelhantes aos encontrados foram reportados para ossos bovinos triturados e moídos após a calcinação a 700, 800, 900 e $1000^{\circ} \mathrm{C}[8]$.

Por meio das análises de FT-IR das amostras calcinadas a $800{ }^{\circ} \mathrm{C}$ e $1000{ }^{\circ} \mathrm{C}$ não é possível observar diferenças significativas entre os espectros (Fig. 2). Os dados mostram pequenos picos nos comprimentos de ondas 1465-1421 $\mathrm{cm}^{-1}$ e $881 \mathrm{~cm}^{-1}$, identificados como carbonato $\left(\mathrm{CO}_{3}^{2-}\right)$. Uma intensa banda localizada no comprimento de onda 1030 $\mathrm{cm}^{-1}$ indica a presença de fosfato de cálcio $\left(\mathrm{PO}_{4}^{3-}\right)$ e os picos registrados nos comprimentos de onda 1089 e $881 \mathrm{~cm}^{-}$ ${ }^{1}$ podem ser indicativos de $\mathrm{HPO}_{4}^{2-}$ [8]. Pode-se inferir a partir destes resultados que a calcinação dos ossos foi adequada, pois segundo a literatura pode haver a formação de grupos cianetos adsorvidos na superfície das partículas (comprimentos de onda 2015 e $2204 \mathrm{~cm}^{-1}$ ) quando a calcinação ocorre em ambientes pouco oxidantes [5]. Outros trabalhos sugerem que, ao invés de grupos cianetos,

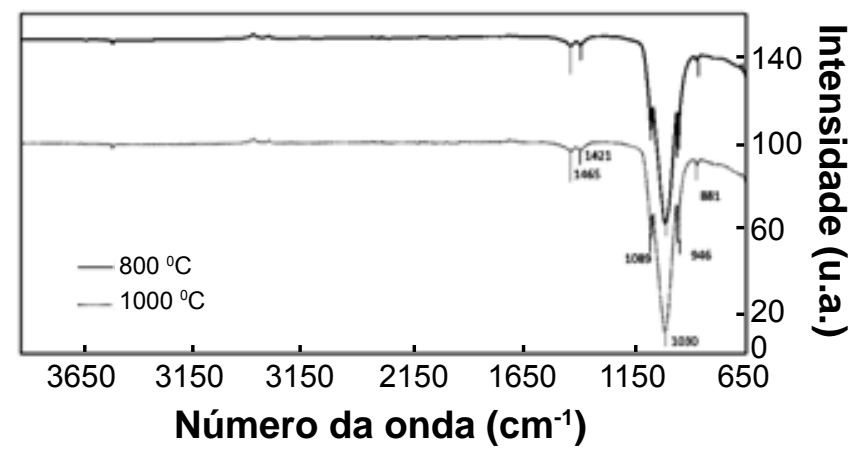

Figura 2: Curvas obtidas por espectroscopia por infravermelho dos ossos calcinados a $800{ }^{\circ} \mathrm{C}$ e $1000{ }^{\circ} \mathrm{C}$.

[Figure 2: Infrared spectroscopy curves of bovine bone calcined at $800^{\circ} \mathrm{C}$ and $1000^{\circ} \mathrm{C}$.]

sejam grupos de carbonatos $\left(\mathrm{CO}\right.$ e $\left.\mathrm{CO}_{2}\right)$ adsorvidos sobre a superfície do osso, pois estes grupos apresentam maior estabilidade química com o fosfato de cálcio e se encontram nos mesmos comprimentos de onda que os cianetos [9].

Os resultados da difração de raios $\mathrm{X}$ podem ser vistos na Fig. 3 e mostram uma única fase cristalina, identificada como hidroxiapatita (ICDD 09-4320) para as amostras calcinada a 800 e $1000{ }^{\circ} \mathrm{C}$. A temperatura de calcinação mais elevada não provocou a alteração da composição de fases das amostras analisadas. Foi mostrada a presença de hidroxiapatita até a queima em $1200{ }^{\circ} \mathrm{C}$ de uma composição de porcelana de ossos, por análise em difração de raios $\mathrm{X}$ [10].

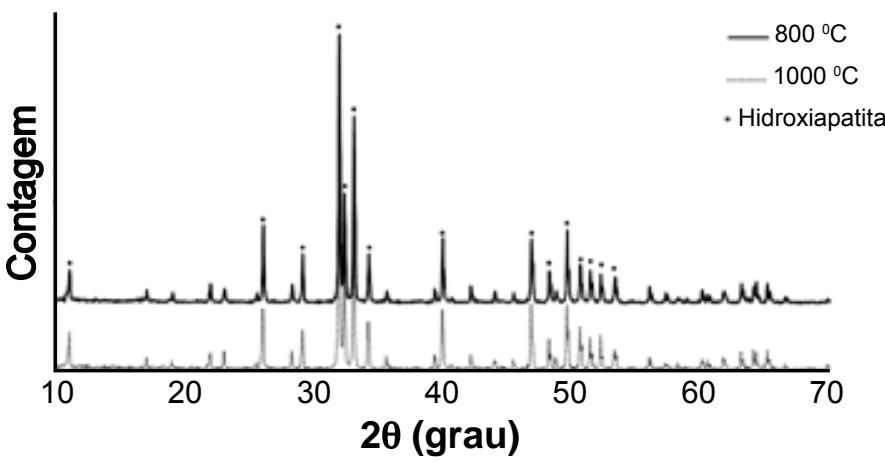

Figura 3: Difratograma de raios $\mathrm{X}$ dos ossos calcinados a $800{ }^{\circ} \mathrm{C}$ e $1000^{\circ} \mathrm{C}$. Fase única detectada: hidroxiapatita.

[Figure 3: X-ray diffraction patterns of the bovine bones calcined at $800^{\circ} \mathrm{C}$ and $1000^{\circ} \mathrm{C}$. Detected phase: hydroxyapatite.]

A maior influência da temperatura de calcinação foi detectada em relação à área superficial (Tabela III). Os resultados mostram que quanto maior a temperatura de calcinação, menor é a área superficial das amostras. Resultado semelhante a este foi publicado para a hidroxiapatita sintética [11]. A Tabela II mostra que D10\% é um pouco maior para calcinação em $1000^{\circ} \mathrm{C}$, o que está de acordo com o resultado da Tabela III, considerando que a fração mais fina representa a maior área superficial. 
Tabela III - Área superficial dos ossos bovinos calcinados a $800{ }^{\circ} \mathrm{C}$ e $1000{ }^{\circ} \mathrm{C}$.

[Table III - Specific surface area of the calcined bovine bone at $800{ }^{\circ} \mathrm{C}$ and $1000{ }^{\circ} \mathrm{C}$.]

\begin{tabular}{ccc}
\hline Ossos calcinados & $800^{\circ} \mathrm{C}$ & $1000^{\circ} \mathrm{C}$ \\
\hline $\mathrm{ASE}\left(\mathrm{m}^{2} / \mathrm{g}\right)$ & 11,86 & 3,01 \\
\hline
\end{tabular}
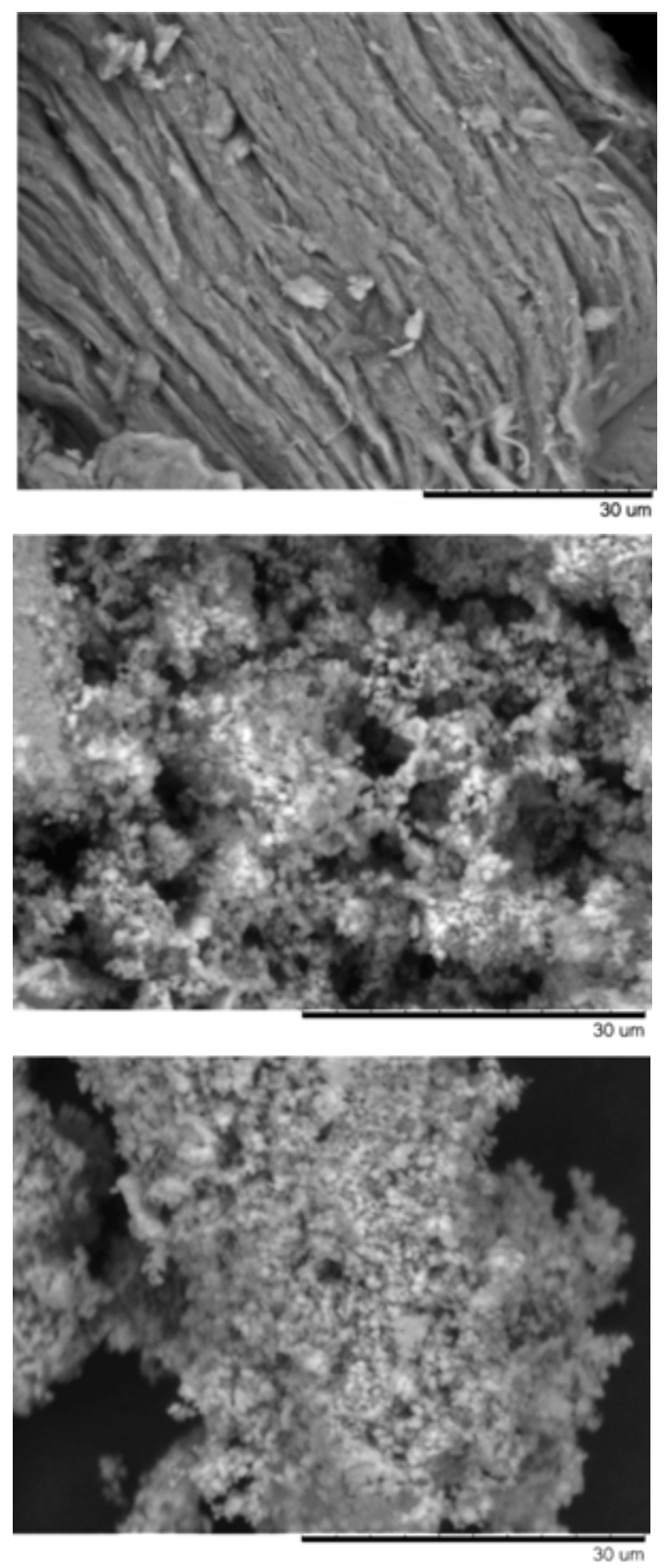

Figura 4: Micrografias obtidas por microscopia eletrônica de varredura dos ossos (A) in natura (B) calcinado a $800{ }^{\circ} \mathrm{C}$ e $(\mathrm{C})$ calcinado a $1000^{\circ} \mathrm{C}$.

[Figure 4: Scanning electron microscopy micrographs of bone $(A)$ in nature (B) calcined at $800^{\circ} \mathrm{C}$ and (C) at $1000^{\circ} \mathrm{C}$.]
A observação do material por meio de microscopia eletrônica de varredura exibe uma mudança na morfologia das partículas após a calcinação. A Fig. 4 ilustra o pó de ossos in natura, o material moído e calcinado a $800{ }^{\circ} \mathrm{C}$ e $1000{ }^{\circ} \mathrm{C}$, respectivamente.

$\mathrm{O}$ material in natura apresenta aspecto fibroso devido à presença de matéria orgânica existente na matriz óssea. Após a calcinação, a parte orgânica é removida restando apenas às partículas de hidroxiapatita. Para ambas as temperaturas de calcinação o material apresenta morfologia similar, porém com tamanhos de partículas/grãos diferentes devido ao tratamento térmico.

\section{Caracterização reológica de suspensões de ossos} calcinados

A Fig. 5 mostra as curvas comportamento reológico de quatro suspensões de ossos calcinados aos quais se diferem pela concentração de sólidos. Os comportamentos observados mostraram-se similar à pesquisa realizada anteriormente [12]. Os dados obtidos mostram que em baixas concentrações de sólidos $55 \%$ e $60 \%$ as suspensões apresentam um comportamento próximo ao de um fluído newtoniano, pois a relação da taxa de cisalhamento e tensão é praticamente linear. Para maiores concentrações de ossos as suspensões passam a exibir uma tendência ao comportamento pseudoplástico.

A transição do comportamento newtoniano para pseudoplástico é atribuída ao aumento da concentração de sólidos. Este fator, dificulta a orientação das partículas em direção à tensão de cisalhamento elevando a viscosidade, Fig. 6 [11]. O aumento da concentração de sólidos em uma suspensão leva ao aumento da viscosidade, cujos fatores são relacionados pela equação de Mooney [13].

A Fig. 7 ilustra a influência da temperatura de calcinação sobre a curva de dispersão de suspensões de ossos. Os

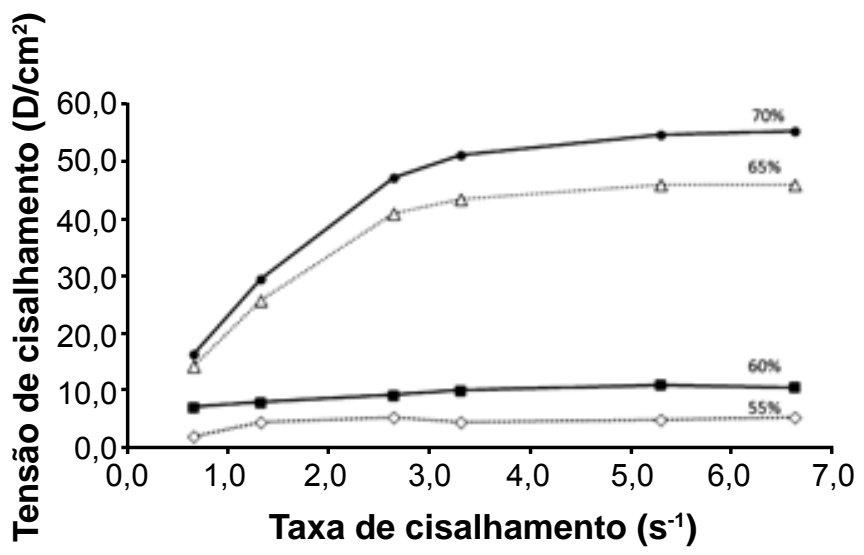

Figura 5: Curvas reológicas das suspensões de ossos com diferentes concentrações de sólidos - 0,2\% de dispersante poliacrilato/Sokalan.

[Figure 5: Rheological curves of the suspensions of bone with different solid concentrations - 0 , 2\% polyacrylate dispersant/ Sokalan.] 


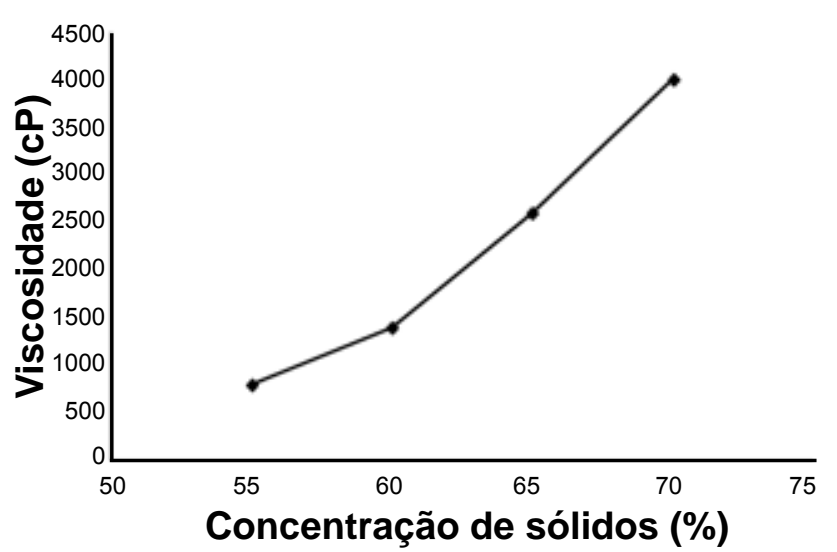

Figura 6: Relação entre a concentração de sólidos e viscosidade aparente (percentual de dispersante Sokalan 0,2\%, Taxa de cisalhamento $\left.26,4 \mathrm{~s}^{-1}\right)$.

[Figure 6: Relation between solids concentration and viscosity (percentage of dispersant Sokalan 0.2\%, shear rate $26.4 \mathrm{~s}^{-1}$.]

resultados mostram que a calcinação em maior temperatura propicia o uso de menor quantidade de dispersante para atingir uma viscosidade próxima à zero. Além disso, a viscosidade inicial para os ossos calcinados a $1000^{\circ} \mathrm{C}$ é inferior à viscosidade inicial dos ossos calcinados a $800^{\circ} \mathrm{C}$.

Esses dados estão de acordo com os resultados obtidos para área superficial. Partículas que possuem maior área superficial têm uma maior área de contato sólidolíquido, por conseguinte, necessitam de maior quantidade de dispersante para o recobrimento total das mesmas. Partículas com área específica menor necessitam de uma menor quantidade de dispersante para tornar efetiva a força de repulsão entre partículas [13, 14].

Os resultados referentes à efetividade dos dispersantes

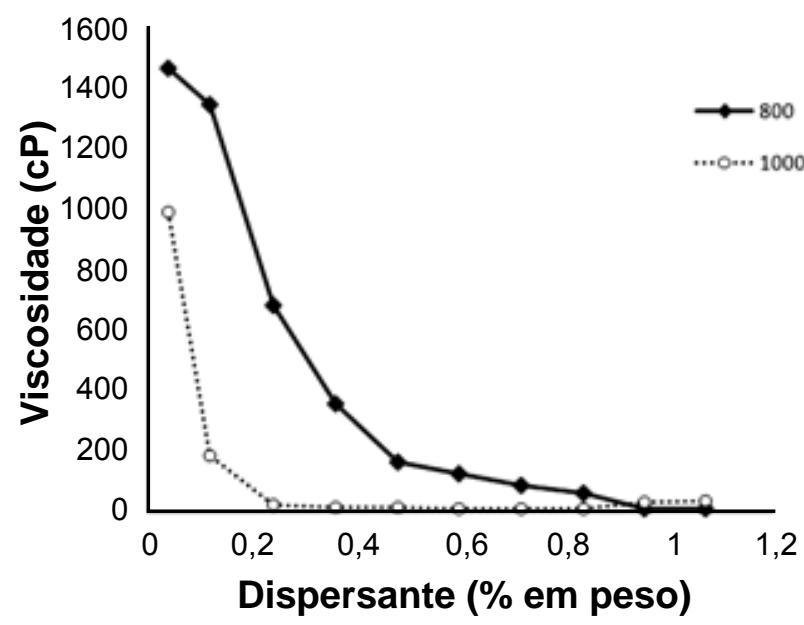

Figura 7: Influencia da temperatura de calcinação sobre a viscosidade aparente da suspensão de ossos com concentração de sólidos 65\%. Taxa de cisalhamento $26,4 \mathrm{~s}^{-1}$. Dispersante Sokalan. [Figure 7: The influence of calcination temperature on the apparent viscosity of the suspension with bone with the solid concentration 65\%. Shear rate 26.4 s-1. Dispersant Sokalan.]

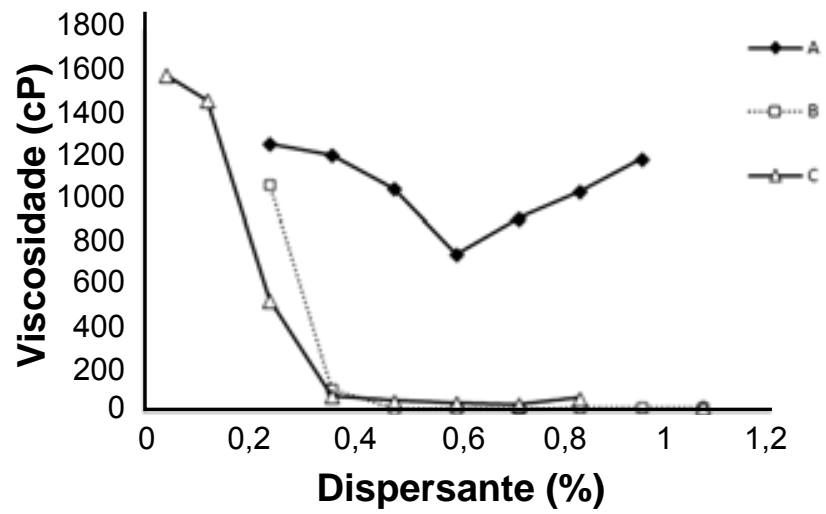

Figura 8: Influencia da concentração de diferentes dispersantes sobre a viscosidade aparente. Suspensão com $65 \%$ de sólidos. Taxa de cisalhamento $26,4 \mathrm{~s}^{-1}$.

[Figure 8: Influence of different concentration of dispersant on the viscosity. Suspension with $65 \%$ solids. Shear rate $26.4 \mathrm{~s}^{-1}$.]

estudados estão apresentados na Fig. 8. Como era de esperar, a adição de dispersante na suspensão de ossos reduz a viscosidade da mistura. Os dados de viscosidade mostram que a eficiência do silicato de sódio (A) foi menor quando comparada com outros dispersantes de poliacrilato (B e C). A viscosidade mínima atingida pelo dispersante A ficou em $\sim 800 \mathrm{cP}$, enquanto, a viscosidade mínima atingida pelos poliacrilatos B e C, respectivamente Sokalan e Diperlan, aproximou-se de zero, para a formulação com a concentração de sólidos de $65 \%$. O uso de polieletrólitos tem apresentado grande eficiência na dispersão de suspensões de hidroxiapatita (HAP), sendo possível preparar suspensões com uma concentração de $73 \%$ em peso de sólidos [12]. Outros estudos com dispersantes à base de poliacrilato também mostraram maior eficiência na estabilização de porcelana de ossos, com esse tipo de dispersante [9]. Ressalta-se que a curva de dispersão para o silicato de sódio não apresenta patamar, ou seja, não há

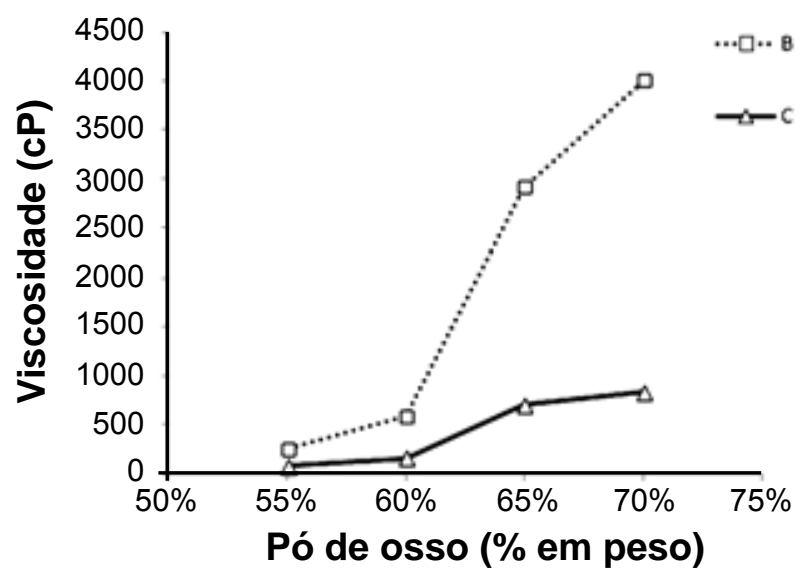

Figura 9: Relação entre os dispersantes B e C (Sokalan e Disperlan, respectivamente) e a concentração de sólidos em suspensão percentual de dispersante $0,15 \%$. Taxa de cisalhamento $26,4 \mathrm{~s}^{-1}$. [Figure 9: Relation between the dispersant B and C (and Sokalan Disperlan, respectively) and the concentration of suspended solids percentage of dispersant $0.15 \%$. Shear rate $26.4 \mathrm{~s}^{-1}$.] 
um intervalo de dispersão, o que praticamente inviabiliza o uso industrial do mesmo, para estas condições de teste.

A Fig. 9 exibe a eficiência dos poliacrilatos testados em relação ao aumento da concentração de ossos em solução. De acordo com os dados obtidos, o dispersante $\mathrm{C}$ torna-se mais eficaz do que o dispersante $\mathrm{B}$ em maiores percentuais de sólidos. Estudos apontam que a eficiência dos poliacrilatos é fortemente influenciada pelo peso molecular médio das cadeias. Quando o sistema não atinge o estado defloculado, a tixotropia é uma característica reológica marcante, no entanto, quando defloculadas as suspensões apresentam comportamento reológico praticamente independente do tempo [15].

\section{CONCLUSÕES}

O tratamento térmico dos ossos bovinos a $800{ }^{\circ} \mathrm{C}$ e $1000{ }^{\circ} \mathrm{C}$ mostrou uma pequena influência sobre a granulometria, mas não alterou as fases presentes e as propriedades químicas dos ossos calcinados. No entanto, a área específica das partículas mostrou-se fortemente afetada pela temperatura. Quanto maior a temperatura de calcinação, menor a área específica das partículas de hidroxiapatita. $\mathrm{O}$ estudo reológico mostrou que o silicato de sódio é menos eficaz do que os poliacrilatos na dispersão da suspensão de ossos. Entre os poliacrilatos testados, o agente dispersante da marca Disperlan mostrou-se mais eficaz na defloculação de suspensões com maior percentual de sólidos. Este fato pode estar atribuído à maior cadeia polimérica do mesmo. A temperatura de calcinação revelou influenciar diretamente na reologia das suspensões de ossos, devido à sua influência na área superficial das partículas. Os resultados encontrados mostraram que quanto menor a área superficial, menor percentual de dispersante será necessário para estabilizar uma suspensão de ossos. Considerando-se o tipo de ossos analisados, a temperatura de calcinação de $1000^{\circ} \mathrm{C}$ foi mais favorável às propriedades almejadas em uma barbotina.

\section{AGRADECIMENTOS}

Ao apoio financeiro do CNPq (Proc. 554262/2010-0) e ao coordenador do Laboratório de cerâmicos - LACER da Universidade Federal do Rio Grande do Sul - UFRGS Prof. Dr. C. P. Bergmann.

\section{REFERÊNCIAS}

[1] S. Wardell, "Porcelan and Bone China", Rambush: Crowood Press (2004) p. 176.

[2] S. R. Bragança, C. P. Bergmann, Produção de porcelana de ossos e caracterização de suas propriedades técnicas, Cerâmica 52, 322 (2006) 205-212.

[3] P. Rado, "Bone china", Ceram. Monographs - A Handbook of Ceramics, Verlag Schmidt GmbH Freiburg i. Brg., Alemanha (1981).

[4] D. Gouvêa, S. Bernard, G. A. V. Alatrsita, S. M. Tofolli, Efeito da temperatura de calcinação nas propriedades de ossos bovinos para a fabricação de porcelana de ossos, Cerâmica 53, 329 (2007) 423-428.

[5] J. J. Cooper, Bone for Bone china, Brit. Ceram. Trans. 94, 4 (1995) 165-168.

[6] K. Hoshi, Fine structure of bone matrix calcification, J. Oral Biosci. 54 (2012) 19-24.

[7] C. M. da Rocha Miranda, "Argilas para Aplicação na Indústria de Louça Sanitária: design e fabrico", Diss. Mestrado, Engenharia Cerâmica e do Vidro, Universidade de Aveiro, Portugal (2008).

[8] C. Y. Ooi, M. Hamdi, S. Ramesh, Properties of hydroxyapatite produced by annealing of bovine bone, Ceram. Int. 33 (2007) 1171-1177.

[9] G. A. Alatrista, "Preparação e estabilização de uma suspensão de porcelana de ossos", Diss. Mestrado, Engenharia, S. Paulo, SP (2008).

[10] Y. Iqbal, P. F. Messer, W. E. Lee, Brit. Ceram. Trans. 99, 5 (2000) 193-199.

[11] M. K. Herliansyah, M. Hamdi, A. Ide-Ektessabi, M. W. Wildan, J. A. Toque, The influence of sintering temperature on the properties of compacted bovine hydroxyapatite, Mater. Sci. Eng. C 29 (2009) 1674-1680.

[12] F. Lelièvre, D. B. Assollant, T. Chatier, Influence of power characteristics on the rheological behavior of hydroxyapatite slurries, J. Mater.Sci.: Mater. Medicine 7 (1996) 489-494.

[13] R. H. Perry, C. H. Chilton, "Chemical Engineers' Handbook", $5^{\text {th }}$ Ed., McGraw-Hill, Nova York, EUA (1973).

[14] J. S. Reed, "Principles of Ceramics Processing", $2^{\text {nd }} E d$. , John Wiley \& Sons (1998).

[15] F. S. Ortega, V. C. Pandolfelli, J. A. Rodrigues, P. A. Sepulveda, Defloculação e propriedades reológicas de suspensões de alumina estabilizadas com dispersantes poliacrílicos. Ceram. Ind. 2 (1997) 34-37.

(Rec. 12/11/2013, Ac. 20/10/2013) 